\title{
1 Copper and Cobalt Improve the Acid Resistance of Alkali-Activated Cements
}

2 Juan Pablo Gevaudan ${ }^{1}$, Alejandro Caicedo-Ramirez ${ }^{l}$, Mark Hernandez ${ }^{1}$, Wil V. Srubar III ${ }^{1+}$

$3{ }^{1}$ Department of Civil, Environmental, and Architectural Engineering, University of Colorado Boulder,

4 Boulder, Colorado USA. ${ }^{\dagger}$ Corresponding Author 1111 Engineering Drive, ECOT 441 UCB 428, Boulder,

5 Colorado USA 80309. T +1 303492 2621, E: wsrubar@colorado.edu

Abstract

Experimental evidence of a new acid degradation mechanism in alkali-activated cements (AACs) microdoped with copper $(\mathrm{Cu})$ and cobalt $(\mathrm{Co})$ is presented in this work. $\mathrm{Cu}$ and Co incorporation into binary metakaolin and basic oxygen furnace (BOF) slag-based AACs reduced bulk permeable porosity and acid penetration and retarded the formation of calcium sulfate phases upon exposure to acid. Analysis of microstructural evolution and elemental mobility using X-ray diffraction and electron microprobe analysis (EMPA) showed that $\mathrm{Cu}$ and $\mathrm{Co}$ doping was associated with major differences in AAC leaching patterns when exposed to sulfuric acid. Converging lines of evidence suggest that acid resistance is improved by the preferential mobilization of $\mathrm{Cu}$ and $\mathrm{Co}$, along with other multivalent cations (i.e., magnesium), at the acid degradation front(s), stabilizing the AAC binder and inhibiting further deterioration.

\section{Introduction}

Unanticipated microbial-induced concrete corrosion (MICC) continues to challenge the underground conduit networks that make up an important part of urban infrastructure. One of the most aggressive and ubiquitous forms of MICC stems from the biologically mediated production of sulfuric acid in sewers. Population centers around the world share this serious and growing problem [1]. In the United States, local governments spend approximately $\$ 50$ billion in the construction, operation, and maintenance of over 800,000 miles of sewers annually [2], [3]. In order to rehabilitate and expand the wastewater infrastructure, the United States Environmental Protection Agency estimates that \$271 billion is needed over the next generation, a substantial fraction of which is dedicated to directly respond to widespread biogenic corrosion that is significantly reducing the service life of buried sewers [3], [4]. Sewer service life reductions result from the fact that conventional ordinary portland cement (OPC) concrete is rapidly compromised by biogenic sulfuric acid attack, producing gypsum and amorphous silica from the cementitious binder [1], [5]. The non-load bearing quality of gypsum leads to severe structural deterioration and, ultimately, pipe failure [5], [6], [7]. Mitigation strategies for microbial-induced concrete corrosion are often short-term, relatively expensive, and site-limited. In order to provide in-situ acid protection for OPC concrete sewers, operators have used

33 surface coatings and linings, concrete binder additives, and, even, antimicrobial additives [8]-[10]. As an 34 example, a popular mitigation practice includes the use of acid resistant, cured-in-place resins. While 
seemingly effective in resisting acid exposure, the associated cost of these materials is high $(\$ 390-900$ per linear meter), they require special curing conditions, and may not prevent corrosive gas infiltration, seriously compromising the effectiveness of this mitigation practice [11]. Further, with the exception of antimicrobial additives, these mitigation strategies do not address one of the underlying causes of MICC in these environments: acidophilic microbial growth. As a result, this study has focused on the incorporation of biocidal metals that, in micromolar concentrations, can function as antimicrobial agents into an alkali-activated cement (AAC), an acid-resistant alternative to OPC [10], [12].

\subsection{Alkali-activated cements and acid durability}

43 A growing cohort of researchers has shown that AACs can provide better acid resistance compared to

44 OPC. Acid resistance in AACs is dependent on a number of physical and chemical factors, including acid 45 type, concentration, activity, and the AACs' chemical composition [13]-[17]. Increased acid resistance

46 has been attributed to the formation of decalcified and modified aluminosilicate gel upon exposure to acid

47 [18]-[23], which has been shown to delay the acid degradation process [18].

48 Deterioration of AACs exposed to strong acids initiates via exchange between interlayered alkali cations $\left(\mathrm{Na}^{+}, \mathrm{K}^{+}, \mathrm{Ca}^{+2}, \mathrm{Mg}^{+2}\right)$ and hydronium ions $\left(\mathrm{H}_{3} \mathrm{O}^{+}\right)$[24]. This exchange leads to destabilization of the aluminosilicate framework, resulting in electrophilic attack of Si-O-Al bonds and the formation of Si-OH and $\mathrm{Al}-\mathrm{OH}$ groups [22]. While $\mathrm{Si}-\mathrm{OH}$ compounds are believed to form an amorphous silica with some beneficial properties [13], [14], [18], the formation of Al-OH results in dealumination of the aluminosilicate binder [13], [14]. Initial cation exchange leads to decalcification of the cementitious binder and formation of soluble salts, namely calcium acetate when exposed to acetic acid or gypsum when exposed to sulfuric acid [18]. In addition to soluble products, fissure cracks are formed likely due to destabilization of the aluminosilicate framework, which results in a loss of mechanical integrity [22].

\subsection{Scope of Work}

58 Motivated by previous work related to antimicrobial metals [25] and acid-resistant AACs, the aim of this study was to experimentally investigate the effect of incorporating micro-doses of heavy metals, namely copper $(\mathrm{Cu})$ and cobalt $(\mathrm{Co})$, on the acid resistance of AACs. Three samples of binary metakaolin- and metal-doped basic oxygen furnace (BOF) slag-based AACs were prepared and exposed to sulfuric acid. Acid exposure was correlated with changes in mineralogy, chemical composition, and physical properties, including bulk permeable porosity and acid corrosion depth. Microstructural evolution and elemental mobility were also investigated via X-ray diffraction and electron microprobe analysis (EMPA), respectively, after semi-dynamic leaching in sulfuric acid solutions.

\section{Materials and Experimental Methods}

\subsection{Materials}


USA), and Metakaolin (MK) (MetaMax), supplied by BASF Chemical Corporation (Georgia, USA), were used as aluminosilicate precursors for alkali-activation. $\mathrm{Cu}\left(\mathrm{NO}_{3}\right)_{2}(99 \%$ purity, Acros Organics) and $\mathrm{Co}\left(\mathrm{NO}_{3}\right)_{2}(99 \%$ purity, Acros Organics) were both utilized to adsorb heavy metals onto the BOF-S precursor.

\subsection{Experimental Methods}

\subsubsection{Copper (Cu) and Cobalt (Co) adsorption}

Batch heavy metal (i.e., $\mathrm{Cu}, \mathrm{Co}$ ) adsorption onto BOF-S was performed as follows. First, $10 \mathrm{~g}$ of $\mathrm{Cu}\left(\mathrm{NO}_{3}\right)_{2}$ were added to one liter of deionized water until completely dissolved. Next, $50 \mathrm{~g}$ of slag (Sieve No.20: $841 \mu \mathrm{m}$ ) were added to the solution and mixed overnight at $150 \mathrm{rpm}$ and room temperature. After this process, the $\mathrm{Cu}$-laden slag $(\mathrm{Cu}-\mathrm{S})$ was separated from the solution using qualitative filter paper (No.1, Whatman), rinsed with water to remove any unattached particles, and oven dried at $40^{\circ} \mathrm{C}$. A similar procedure was performed to create the same material which was laden with $\mathrm{Cu}$ and $\mathrm{Co}(\mathrm{Cu} / \mathrm{Co}-\mathrm{S})$; however, in addition to $\mathrm{Cu}\left(\mathrm{NO}_{3}\right)_{2}, 10 \mathrm{~g} / \mathrm{L}$ of $\mathrm{Co}\left(\mathrm{NO}_{3}\right)_{2}$ were dissolved in the initial solution prior to slag addition. Next, the BOF-S was ground in mill capsules with clean, packed yttrium-stabilized zirconium grinding beads (American Elements) using a McCrone micronizing mill. A No.100 sieve was used to ensure a sub- $149 \mu \mathrm{m}$ particle size.

Table 1 shows the chemical composition of all AAC precursors (MK, BOF-S, Cu-S, and $\mathrm{Cu} / \mathrm{Co}-\mathrm{S}$ ) determined by ICP-OES, on a calibrated ARL 3410+, using modifications to a widely accepted technique developed by Farrell et al. [26]. Five $\mathrm{mL}$ of a 7:3 mixture of hydrochloric acid and hydrofluoric acid were combined with $2 \mathrm{~mL}$ of nitric acid and placed in digestion tubes that were maintained at $95^{\circ} \mathrm{C}$ in a digestion block (HotBlock, Environmental Express) for approximately two hours. Samples were then cooled and brought to $50 \mathrm{~mL}$ with a $1.5 \%$ boric acid solution (by mass). The samples were then reheated to $95^{\circ} \mathrm{C}$ for 15 minutes and cooled for analysis. The samples were diluted 10x with deionized water and analyzed with an ICP-OES, as described above. An analytical blank, along with three standards that were made by accurately diluting certified standards, was used for calibration. A basaltic internal standard (Valmont Dike, Colorado USA) of known chemical composition was digested and analyzed to ensure the accuracy of the chemical composition results shown in Table 1. Precursors were supplemented using a reagent-grade sodium silicate $(\mathrm{NaSi})$ solution supplied by Sigma-Aldrich. The chemical composition of the $\mathrm{NaSi}$ solution was determined to have a $\mathrm{SiO}_{2}: \mathrm{Na}_{2} \mathrm{O}$ molar ratio of $2.5\left(\mathrm{SiO}_{2}=27\right.$ wt.\%, $\mathrm{Na}_{2} \mathrm{O}=11$ wt. $\%, \mathrm{H}_{2} \mathrm{O}=62 \mathrm{wt} . \%$ ), as obtained via ICP-OES as previously described.

99 Table 1. Chemical composition of $\mathrm{MK}, \mathrm{BOF}-\mathrm{S}, \mathrm{Cu}-\mathrm{S}$, and $\mathrm{Cu} / \mathrm{Co}-\mathrm{S}$ in weight percent.

\begin{tabular}{lllllllllllll}
\hline Precursor & $\mathrm{SiO}_{2}$ & $\mathrm{Al}_{2} \mathrm{O}_{3}$ & $\mathrm{CaO}$ & $\mathrm{SO}_{4}$ & $\mathrm{Fe}_{2} \mathrm{O}_{3}$ & $\mathrm{~K}_{2} \mathrm{O}$ & $\mathrm{Na}_{2} \mathrm{O}$ & $\mathrm{MgO}$ & $\mathrm{MnO}$ & $\mathrm{Cu}$ & $\mathrm{Co}$ & $\mathrm{P}_{2} \mathrm{O}_{5}$ \\
\hline MK & 52.1 & 41.3 & 0.07 & 0.3 & 0.36 & 0.11 & 0.33 & - & - & - & - & 0.08 \\
BOF-S & 14.7 & 6.6 & 31.7 & 0.4 & 25.8 & $<0.05$ & 0.1 & 10.8 & 2.5 & - & - & 0.7 \\
$\mathrm{Cu}-\mathrm{S}$ & 14.4 & 7.4 & 29.1 & 0.3 & 24.2 & $<0.05$ & 0.1 & 10.7 & 2.6 & 2.4 & - & 0.1
\end{tabular}


Manuscript submitted to:

Cement and Concrete Research

$\begin{array}{lllllllllllll}\mathrm{Cu} / \mathrm{Co}-\mathrm{S} & 13.6 & 6.7 & 28.9 & 0.2 & 26.3 & <0.05 & 0.1 & 6.5 & 2.4 & 1.5 & 1.3 & 0.7\end{array}$

100

\subsubsection{AAC sample preparation}

In this study, AACs were prepared by mixing 66\% MK and 33\% BOF-S by weight with NaSi solution according to the prescribed mix design parameters shown in Table 2. All materials were mixed at room temperature using a Waring PDM112 mixer. To ensure no material residual remained on the sides of the vessel, the mixing procedure was repeated twice: one minute of manual mixing, followed by one minute of mechanical mixing. Samples were then cured inside hermetically sealed plastic containers for $72 \pm 1$ hours at $100 \%$ relative humidity and $22^{\circ} \mathrm{C}$. The constant humidity chamber was prepared according to ASTM E104 by placing a supersaturated salt solution of sodium phosphate (Sigma-Aldrich) inside the plastic containers. After this period, both samples were cured inside a Quincy forced air laboratory oven set to $20^{\circ} \mathrm{C}$ for $25.5 \pm 1.5$ hours.

Paste samples were cast in both small cylinder molds (diameter $2.4 \mathrm{~cm}$, height $1.5 \mathrm{~cm}$ ) used for semidynamic leaching experiments (see Section 2.2.2) and longer cylinder molds (diameter $1.4 \mathrm{~cm}$, height 4 $\mathrm{cm}$ ) that were used to determine acid corrosion depth (see Section 2.2.7).

Table 2. Sample classification and mixture proportions for MK-BOF-S AACs. Important parameters are reported in molar atomic ratios $(\mathrm{Si}: \mathrm{Al}, \mathrm{Na}: \mathrm{Al})$ and molecular $\operatorname{ratios}\left(\mathrm{H}_{2} \mathrm{O}: \mathrm{Al}_{2} \mathrm{O}_{3}\right)$.

\begin{tabular}{|c|c|c|c|c|c|c|}
\hline \multirow{2}{*}{ Mixtures } & \multicolumn{2}{|c|}{ Solids } & \multirow{2}{*}{$\begin{array}{c}\text { Alkali-Activating Solution } \\
\text { Sodium Silicate }(\mathrm{ml})\end{array}$} & \multicolumn{3}{|c|}{ Important Parameters } \\
\hline & MK (g) & Slag (g) & & $\overline{\mathrm{Si}: \mathrm{Al}}$ & $\mathrm{Na}: \mathrm{Al}$ & $\mathrm{H}_{2} \mathrm{O}: \mathrm{Al}_{2} \mathrm{O}_{3}$ \\
\hline Control & 80 & 40 & 122 & 2.0 & 0.8 & 15 \\
\hline Control $+\mathrm{Cu}$ & 80 & 40 & 122 & 2.0 & 0.8 & 15 \\
\hline Control $+\mathrm{Cu} / \mathrm{Co}$ & 80 & 40 & 122 & 2.0 & 0.8 & 15 \\
\hline
\end{tabular}

\subsubsection{Semi-Dynamic Leaching}

Cast samples (diameter $2.4 \mathrm{~cm}$, height $1.5 \mathrm{~cm}$ ) were placed in polypropylene plastic containers with either sulfuric acid solution ( $1 \% \mathrm{v} / \mathrm{v})$ or deionized water at a volume-to-surface area ratio of 10 , as described by ASTM C1308. In addition, samples were suspended by triangle plastic stands to allow full surface exposure to the acidic medium. Exposure media was replaced daily for seven consecutive days for each of the three replicates. Samples of leachate media were taken before each replacement. Prior to characterization, samples were dehydrated by solvent exchange with anhydrous ethanol (200 proof, $0 \%$ $\mathrm{H}_{2} \mathrm{O}$, Decon Labs) and dried at $40^{\circ} \mathrm{C}$ overnight in a Quincy forced air laboratory oven [27]. Leachate media samples were analyzed with ICP-OES and ICP-MS.

\subsubsection{Desorption potential and acid neutralization capacity}

Cured AAC specimens were crushed using a mortar and pestle to pass a No. 100 mesh sieve $(<149 \mu \mathrm{m})$. Solutions containing deionized water and $\mathrm{H}_{2} \mathrm{SO}_{4}(97 \% \mathrm{w} / \mathrm{w})$ were prepared to establish a concentration 
Manuscript submitted to:

Cement and Concrete Research

gradient of $\mathrm{H}_{3} \mathrm{O}^{+}$(expressed as equivalents of acid per $\mathrm{kg}$ of AAC). The powdered specimens were added to the solutions at a liquid-to-solid ratio of 20. Portions of powdered specimens for all three AAC samples were chemically characterized via ICP-OES to determine an initial concentration of elements. Batches were mixed overnight at $150 \mathrm{rpm}$ and room temperature. Final $\mathrm{pH}$ of the solutions was measured and batches were then centrifuged at $5000 \mathrm{rpm}$ for 10 minutes. The supernatant was analyzed for soluble cations using ICP-OES and the solid was oven dried at $40^{\circ} \mathrm{C}$ and analyzed for their mineral profiles on a Siemens D500 X-ray diffractometer. The initial chemical compositions of the powders were compared with the chemical compositions of the supernatant after batch reactions to calculate a leached percentage of each element ( $\mathrm{Si}, \mathrm{Al}, \mathrm{Na}, \mathrm{Ca}, \mathrm{Mg}, \mathrm{Fe}, \mathrm{Cu}$ and $\mathrm{Co}$ ) with respect to the total initial mass of each.

\subsubsection{X-ray diffraction $(X R D)$}

To determine mineralogy, AAC samples were first crushed into a powder with a mortar and pestle. The powder was then prepared for analysis using a modified method based on [28]. The former method was modified to employ corundum as an internal standard instead of zincite. A Siemens D500 X-ray diffractometer was used to acquire energy dispersion patterns for all samples. Samples were analyzed from 5 to 65 degrees $2 \theta$ using $\mathrm{Cu} \mathrm{K \alpha} \mathrm{X}$-ray radiation, with a step size of 0.02 degrees and a dwell time of 2 seconds per step. Mineralogy was identified using Jade software (MDI, Version 9) and the International Centre for Diffraction Data (ICDD) 2003 database. Corundum was used to normalize peak heights between samples and align diffraction patterns.

\subsubsection{Bulk Permeable Porosity}

Permeable porosities were measured using a vacuum saturation method, which was selected because it has improved efficiency compared to conventional laboratory methods for estimating permeable porosity [29]. The method was modified by using anhydrous ethanol in lieu of water to prevent any hydration reactions from occurring during the analysis. Sample volumes were observed by measuring sample dimensions with calibrated micro-calipers and vacuum-saturated with ethanol for 24 hours. The saturatedsurface-dry (SSD) weight was recorded using a Mettler Toledo PL 1502E scale after ethanol-vacuum immersion. Samples were then dried at $40^{\circ} \mathrm{C}$ for 24 hours and their oven-dry (OD) weights were recorded. Permeable porosity was calculated as the difference in SSD mass and OD mass normalized by the density of ethanol $\left(0.803 \mathrm{~g} / \mathrm{cm}^{3}\right)$ all divided by total sample volume.

\subsubsection{Corrosion Depth}

Cast cylindrical samples (diameter $1.4 \mathrm{~cm}$, height $4 \mathrm{~cm}$ ) were wrapped with commercial electrical tape twice at both the curved and bottom surfaces of the cylinder, leaving only one circular face exposed. Samples were submerged in sulfuric acid solution $(1 \% \mathrm{v} / \mathrm{v})$ at a volume-to-surface ratio of 30 to determine corrosion depth in one dimension. After acid exposure, samples were dehydrated by immersion in anhydrous ethanol (200 proof, Decon Labs) and dried at $40^{\circ} \mathrm{C}$ overnight in a Quincy forced air 
laboratory oven [27]. The corrosion layer was qualitatively identified by obvious color change and corrosion depths were quantitatively measured using calipers as previously described. The weak product layer was evaluated by measuring the total height dimension of the sample before and after brushing with a commercial copper wire brush until no additional residue detached from the material.

\subsubsection{Electron Micro-Probe Analysis (EMPA)}

The mobility and fate of elements of interest before and after exposure to sulfuric acid were analyzed by compiling X-ray element maps of $\mathrm{Si} \mathrm{K} \alpha, \mathrm{Al} \mathrm{K} \alpha, \mathrm{S} \mathrm{K} \alpha, \mathrm{Ca} \mathrm{K} \alpha, \mathrm{Na} \mathrm{K} \alpha, \mathrm{Fe} \mathrm{K} \alpha, \mathrm{Mg} \mathrm{K} \alpha$, Co K $\alpha$, and $\mathrm{Cu}$ $\mathrm{K} \alpha$, which were obtained using a JEOL-8230 electron microprobe. In some cases, two maps for $\mathrm{Cu} \mathrm{K} \alpha$ were aggregated to enhance precision. An acceleration voltage of $15 \mathrm{keV}$ and beam current of $100 \mathrm{nA}$ was used for all maps. The electron beam was defocused to 5-6 $\mu \mathrm{m}$ to match the pixel size, and a dwell time of $20 \mathrm{msec}$ was used. Element maps were treated with CalcImage (ProbeSoftware, Inc.) to remove the background using the mean atomic number background correction, and a matrix correction was additionally performed as required for quantitative work [30], [31]. Raw data, expressed as net counts, are semi-quantitative, since each pixel likely represents a mixture of two or more phases. Considering these material limitations, atomic percentages were quantified to discern the central tendencies of bulk Si:Al ratios using statistical analysis. EMPA data were analyzed for statistical significance by utilizing Minitab 18.1 statistical analysis software. The respective intensity scale bars, which differ for each element, are presented in the Supplementary Information.

\section{Experimental Results}

\subsection{Dissolution behavior of AACs}

\subsubsection{Semi-dynamic time-dependent leaching}

The time-dependent leaching behaviors of all samples exposed to deionized water are shown in Figure 1. Elemental leaching decreases with exposure time in all samples and for all elements. Under this scenario, the elements which dominated leaching on a molar basis were silicon ( $\mathrm{Si}$ ) and sodium (Na), while concentrations of other elements were either not present or were below the method detection limit. For example, the Si leaching in the Control sample, on the order of $7.4 \mathrm{mg} / \mathrm{cm}^{2}$ in the first day, decreased $68 \%$ by the second day. No other evidence of elemental leaching was observed.

Formulations containing copper $(\mathrm{Cu})$ and cobalt $(\mathrm{Co})$ exhibited higher normalized leaching of both $\mathrm{Si}$ and $\mathrm{Na}$ in deionized water (Figure 1). The addition of $\mathrm{Cu}$ and $\mathrm{Co}$ increased the leaching of Si by a factor of approximately 3.4 when compared to the Control. While $\mathrm{Na}$ ions exhibit similar leaching behavior as $\mathrm{Si}$ ions in all samples, the addition of $\mathrm{Cu}$ and $\mathrm{Co}$ effectively doubled the $\mathrm{Na}$ leaching output in comparison to the Control.

As shown in Figure 1, acid exposure induces elemental mobility in the AAC matrix, but samples containing $\mathrm{Cu}$ and both $\mathrm{Cu}$ and $\mathrm{Co}$ leach lower amounts of iron $(\mathrm{Fe})$, magnesium $(\mathrm{Mg})$, aluminum ( $\mathrm{Al})$, 
and calcium (Ca) than the Control. While Na leaching does not differ between samples, leaching of $\mathrm{Ca}$ in

197 the samples containing $\mathrm{Cu}$ is lower than the Control after the first day of acid exposure. Similarly, the

198 leaching of the samples containing $\mathrm{Cu}$ is lower than that of the Control for $\mathrm{Fe}, \mathrm{Mg}, \mathrm{Si}$, and $\mathrm{Al}$ ions after

199 one day of exposure. The leaching profile from AAC samples containing both $\mathrm{Cu}$ and Co is also lower

200 after the second day of acid exposure with respect to $\mathrm{Fe}, \mathrm{Mg}$, and $\mathrm{Al}$ ions.
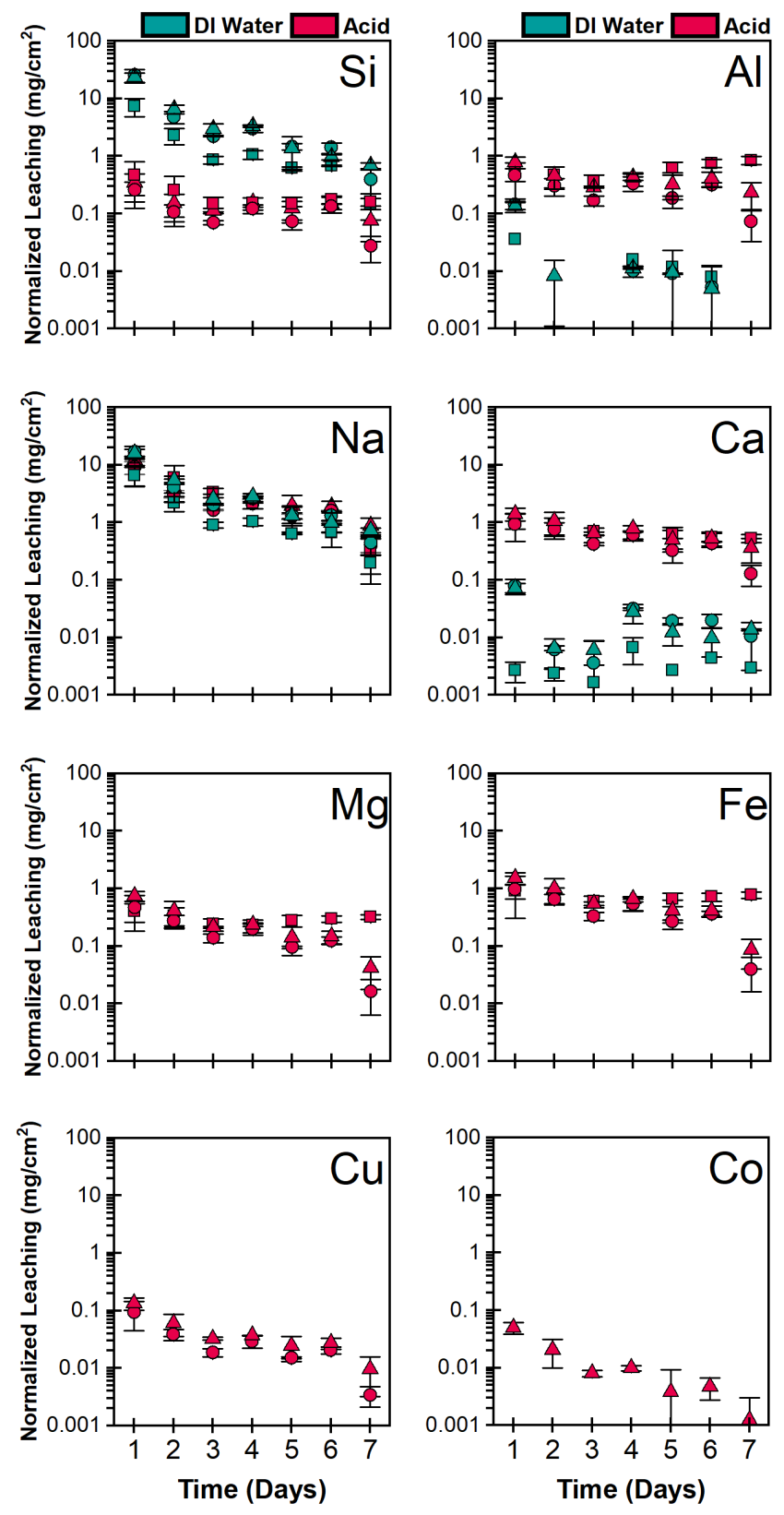

Figure 1. Surface area-normalized daily elemental leaching $\left(\mathrm{mg} / \mathrm{cm}^{2}\right)$ in deionized water (DI water) and sulfuric acid (Acid) over seven days for Control ( $\square$ ), Control $+\mathrm{Cu}(\circ)$, and Control $+\mathrm{Cu} / \mathrm{Co}(\Delta)$. Error bars represent the standard deviation of three replicates. 


\subsubsection{Desorption potential and acid neutralization capacity}

207 From leaching profiles shown in Figure 2, it is evident that all formulations liberated increasing

208 quantities of chemical constituents in response to acid exposure (with the exception of $\mathrm{Si}$ ). The results

209 suggest that cations can be grouped based on the difference between the percentage leached at 8 eq/kg of

210 acid exposure and the percentage leached at the baseline condition ( $0 \mathrm{eq} / \mathrm{kg}$ of acid exposure): (1) mildly

211 affected $(<20 \%$ difference) by acid addition ( $\mathrm{Ca}, \mathrm{Si}, \mathrm{Al})$ and $(2)$ strongly affected $(>20 \%$ difference) by

212 acid addition $(\mathrm{Mg}, \mathrm{Na}, \mathrm{Fe}, \mathrm{Cu}, \mathrm{Co})$. Leached $\mathrm{Ca}$ increases from nondetectable to a stable magnitude of

213 approximately $16 \%$ when acid exposure was above $4 \mathrm{eq} / \mathrm{kg}$. Si and $\mathrm{Na}$ were the only cations leached in

214 the absence of acid. However, net Si leaching declined in response to increasing acid exposures, while Na

215 plateaued at $90 \%$ at or above $6 \mathrm{eq} / \mathrm{kg}$ acid exposure. Al was detected at and above $6 \mathrm{eq} / \mathrm{kg}$ acid exposure,

216 with a maximum leaching of $15 \%$ at $8 \mathrm{eq} / \mathrm{kg}$ acid exposure. Additionally, $\mathrm{Mg}$ and Fe gradually increased

217 presence in response to increasing acid exposures to their respective maxima of $84 \%$ and $68 \%$ when acid

218 exposure conditions were $8 \mathrm{eq} / \mathrm{kg}$. Cu and Co gradually increase their presence in the leachates as well;

219 these metals were not detectable in the absence of acid but equilibrated at approximately $98 \%$ in the

220 leachate at and above $6 \mathrm{eq} / \mathrm{kg}$ acid exposure. 

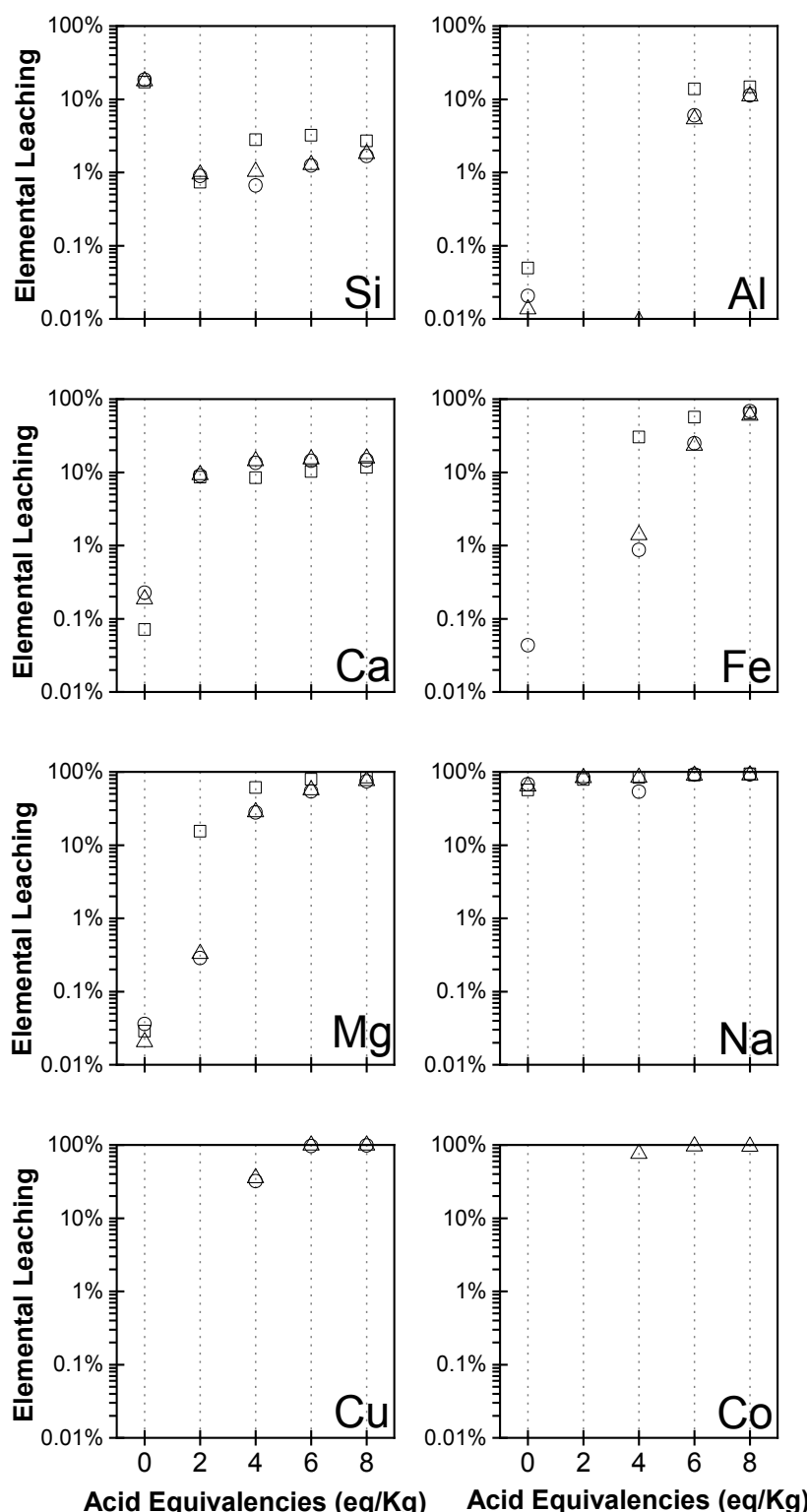

Figure 2. Elemental leachin from pulverized AAC formulations in response to increasing acid concentration (eq $\mathrm{H}_{3} \mathrm{O}^{+} / \mathrm{kg} \mathrm{AAC}$ ) for Control ( $\square$ ), Control $+\mathrm{Cu}(\circ)$, and Control $+\mathrm{Cu} / \mathrm{Co}(\Delta)$ samples.

The $\mathrm{pH}$ at the end of these experiments indicated the neutralization capacity of the different AAC formulations. As seen in Table 3, no significant differences are observed between formulations. $\mathrm{pH}$ values decreased in response to acid addition to $\mathrm{pH} 2$ in an $8 \mathrm{eq} / \mathrm{kg}$ acid solution in all sample 227 formulations.

Table 3. Batch solution $\mathrm{pH}$ after 24 hours of acid exposure at 1:20 solid-to-liquid ratio.

\begin{tabular}{llllll}
\hline & $0 \mathrm{eq} / \mathrm{kg}$ & $2 \mathrm{eq} / \mathrm{kg}$ & $4 \mathrm{eq} / \mathrm{kg}$ & $6 \mathrm{eq} / \mathrm{kg}$ & $8 \mathrm{eq} / \mathrm{kg}$ \\
\hline Control & 11.44 & 9.64 & 5.32 & 3.34 & 2.17 \\
Control $+\mathrm{Cu}$ & 11.39 & 9.65 & 5.23 & 3.33 & 2.23 \\
Control $+\mathrm{Cu} / \mathrm{Co}$ & 11.39 & 9.64 & 5.02 & 3.21 & 2.08 \\
\hline
\end{tabular}




\subsection{Mineralogy}

\subsubsection{Mineralogical response of bulk AACs upon acid exposure}

231 Figure 3 shows mineralogical profiles of the cast (bulk) AAC samples after exposure to different 232 environmental conditions, including sulfuric acid. Salient minerals identified with XRD are listed in

233 Table 4 with the corresponding unit geometry, volume, and density, as determined by each reference 234 standard. Symbols correspond to the peaks identified in Figure 3.

Alkali activation of the Control formulation resulted in a cementitious material with traces of the original mineral composition. Minor mineralogical differences between the raw BOF-S, Cu-S, and $\mathrm{Cu} / \mathrm{Co}-\mathrm{S}$ precursors were initially detected (data not shown; see Supplementary Information). After alkali-activation, traces of quartz, srebrodolskite, merwinite, and wüstite present in the original BOF-S precursor were detected. Data indicate complete reaction of belite, which resulted in the formation of calcium silicate hydrate (C-S-H) phases in all cement samples.

No significant mineral changes were observed between dehydrated AAC samples (Figure 3a), samples at ambient conditions (Figure 3b), or samples exposed to deionized water (Figure 3c).

243 Following exposure to sulfuric acid, however, samples containing $\mathrm{Co}$ and $\mathrm{Cu}$ had notably lower gypsum

244 content compared to the Control (Figure 3d). However, the acid-exposed Control containing $\mathrm{Cu}$ and or

245 Co showed traces of calcium sulfate hydrate (Table 4), a similar mineral, with a larger unit cell volume 246 and lower density.

Table 4. Summary of observed minerals as determined by XRD. Mineral shapes, unit volumes, and densities were obtained using the Jade5 mineral database as a reference standard.

\begin{tabular}{lllllll}
\hline Mineral Name & Stoichiometry & Symbol & Unit Geometry & $\begin{array}{l}\text { Unit Cell } \\
\text { Volume }\left(\AA^{3}\right)\end{array}$ & $\begin{array}{l}\text { Density } \\
\left(\mathrm{g} / \mathrm{cm}^{3}\right)\end{array}$ & PDF \# \\
\hline $\begin{array}{l}\text { Srebrodolskite } \\
\text { Wüstite }\end{array}$ & $\mathrm{Ca}_{2} \mathrm{Fe}_{2} \mathrm{O}_{5}$ & $\mathrm{~S}$ & Orthorhombic & 448 & 4.04 & $00-038-0408$ \\
$\begin{array}{l}\text { Merwinite } \\
\text { Quartz }\end{array}$ & $\mathrm{Fe}_{0.9536} \mathrm{O}$ & $\mathrm{W}$ & Cubic & 78.5 & 5.613 & $01-074-1880$ \\
$\begin{array}{l}\text { Calcium Silicate } \\
\text { Hydrate }\end{array}$ & $\mathrm{Ca}_{3} \mathrm{Mg}\left(\mathrm{SiO}_{4}\right)_{2}$ & $\mathrm{M}$ & Monoclinic & 659.3 & 3.15 & $00-035-0591$ \\
Calcium Sulfate Hydrate & $\mathrm{SiO}_{2}$ & $\mathrm{Q}$ & Hexagonal & 113 & 2.66 & $00-046-1045$ \\
Gypsum & $\mathrm{Ca}_{1.55} \mathrm{SiO}_{3} \cdot \mathrm{x}\left(\mathrm{H}_{2} \mathrm{O}\right)$ & $\mathrm{C}$ & - & - & - & $00-033-0306$ \\
Corundum & $\mathrm{CaSO}_{4} \cdot 0.62\left(\mathrm{H}_{2} \mathrm{O}\right)$ & $\mathrm{H}$ & Hexagonal & $2,119.90$ & 0.115 & $00-041-0225$ \\
& $\mathrm{Al}_{2} \mathrm{O}_{3}$ & $\mathrm{G}$ & Monoclinic & 495.4 & 2.32 & $00-033-0311$ \\
& & $\mathrm{O}$ & - & 253.54 & 3.98 & $00-010-0173$ \\
\hline
\end{tabular}



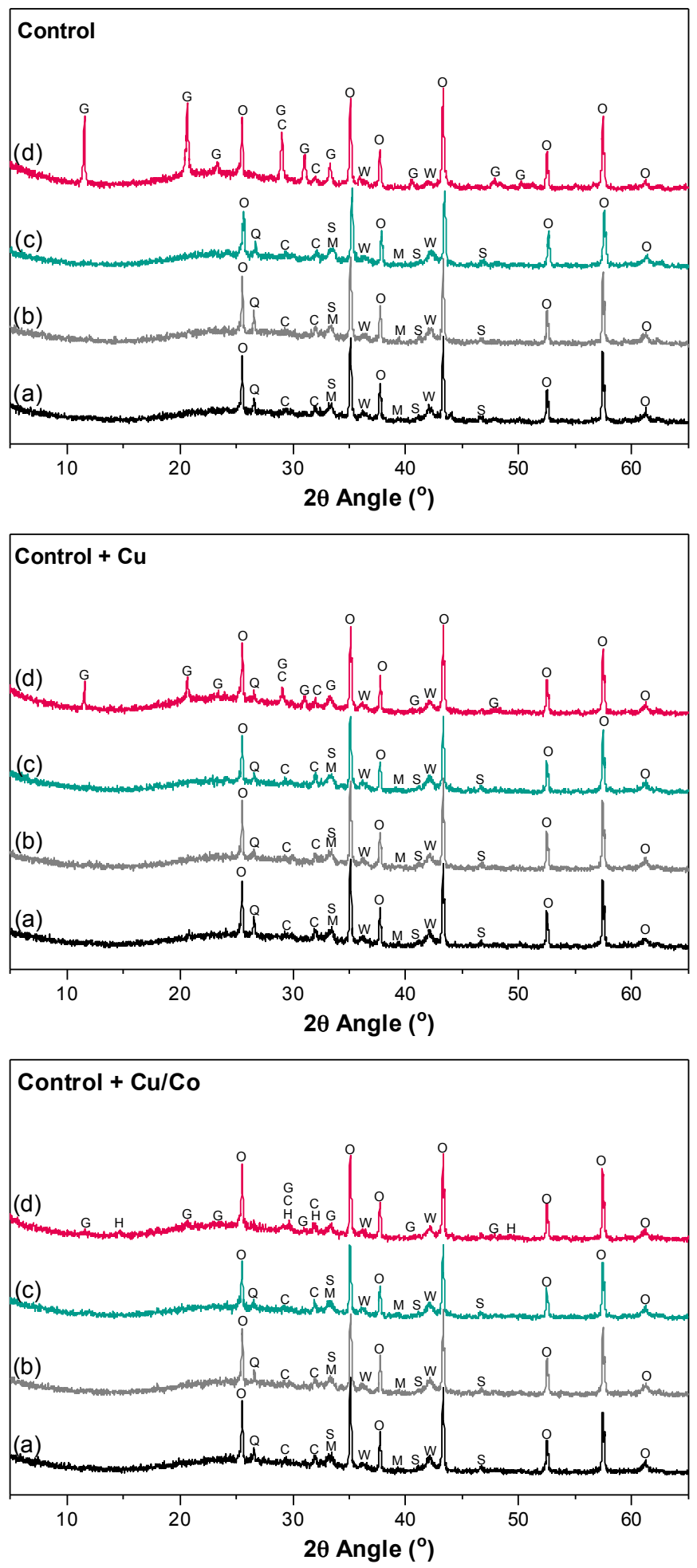

Figure 3. XRD patterns for (a) dehydrated samples, and samples exposed to: (b) ambient conditions

$251\left(22^{\circ} \mathrm{C}\right.$ and $30 \%$ relative humidity), (c) deionized water, and (d) sulfuric acid. S: srebrodolskite, G:

252 gypsum, H: calcium sulfate hydrate, C: calcium silicate hydrate (C-S-H), W: wüstite, Q: quartz, M: merwinite, and O: corundum. 


\section{$254 \quad 3.2 .2 \quad$ Mineralogical response of powdered AACs upon acid exposure}

255 As judged by acid equivalents, acid strength affected the formation of gypsum and other minerals (Figure

256 4) in powderized samples. As discussed, powdered samples were used in conjunction with cast (bulk)

257 samples to explicitly study element liberation and mineral formation and identify changes in mineralogy

258 in response to acid strength. AAC powders exposed to sulfuric acid formed gypsum when acid additions

259 were greater than $4 \mathrm{eq} / \mathrm{kg}$, with minimal changes in the diffraction intensity of gypsum noted in response

260 to increased acid strength. Results of AAC powders exposed to deionized water (Figure 4a) indicate the

261 presence of both quartz and srebrodolskite, further substantiating the results obtained and shown in

\section{$262 \quad$ Figure 3.}



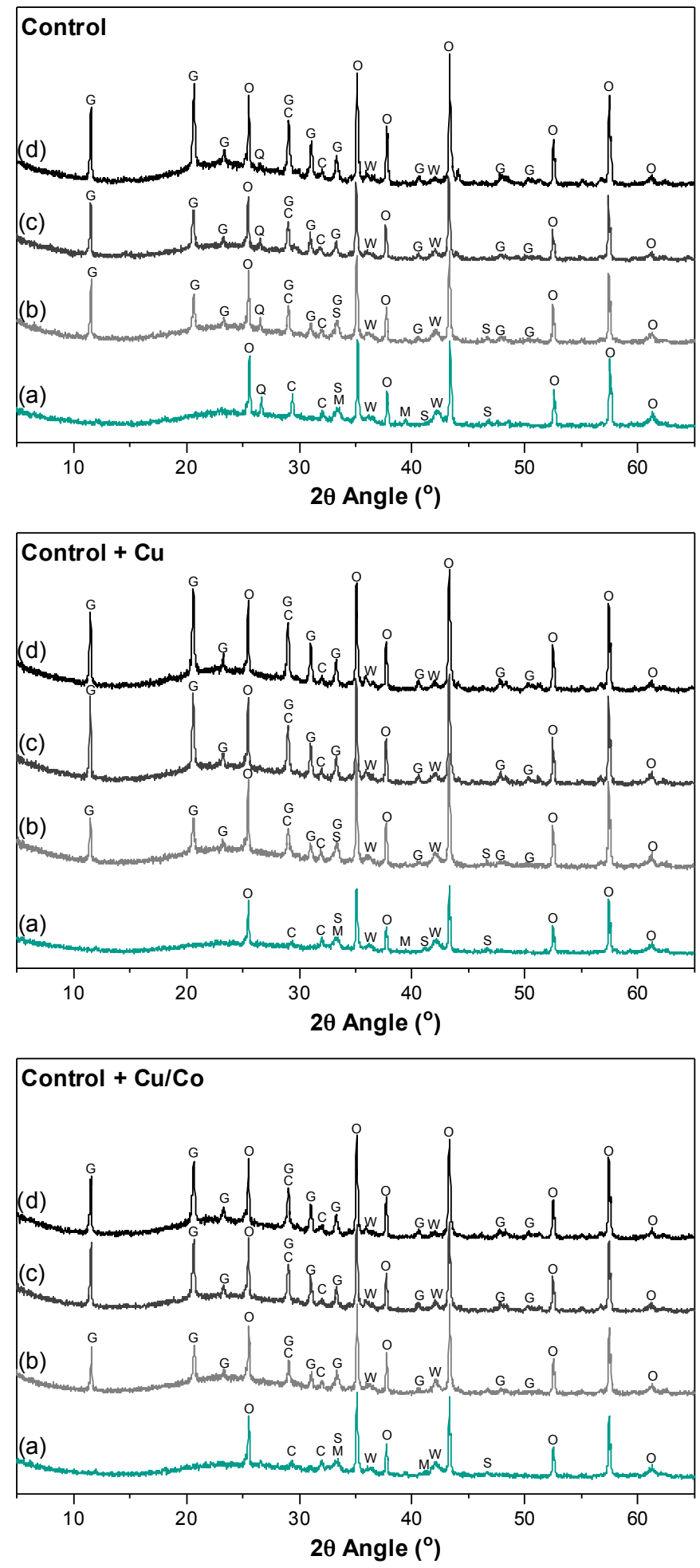

Figure 4. XRD patterns for all samples exposed to increasing concentrations of sulfuric acid: (a) 0 eq, (b)

2644 eq, (c) 6 eq, and (d) 8 eq. S: srebrodolskite, G: gypsum, H: calcium sulfate hydrate, C: calcium silicate

265 hydrate (C-S-H), W: wüstite, Q: quartz, M: merwinite, O: corundum. 


\subsection{Permeable Porosity}

267 After exposure to deionized water and sulfuric acid, all AAC materials increased in permeable porosity

268 (Figure 5). The Control exhibited the highest permeable porosity of all sample formulations when

269 exposed to either water or acid. When exposed to the same, samples including $\mathrm{Cu}$ and Co resulted in

270 lower porosities when compared to the otherwise identical Control. Comparison between Control $+\mathrm{Cu}$

271 and $\mathrm{Control}+\mathrm{Cu} / \mathrm{Co}$ samples indicate no statistically significant difference in porosity upon exposure to

272 water. However, when exposed to acid, the Control $+\mathrm{Cu} / \mathrm{Co}$ sample exhibited the lowest porosity overall.

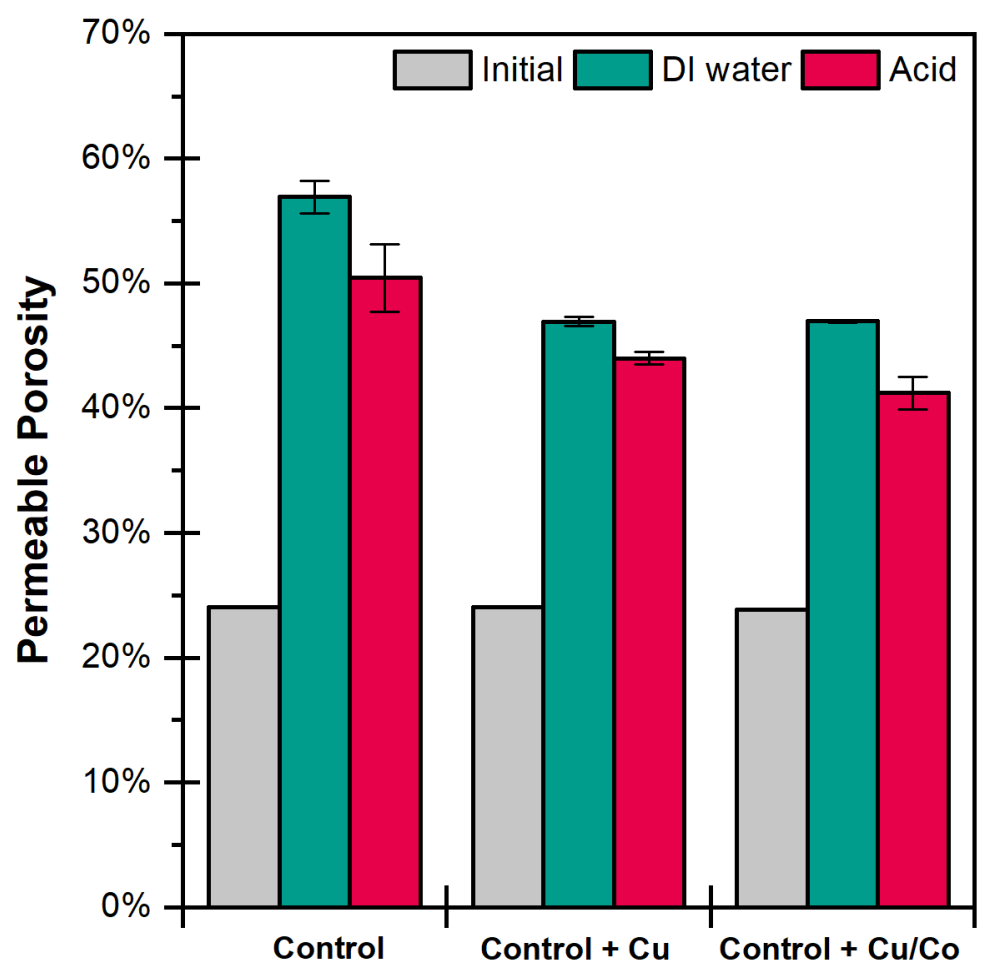

274 Figure 5. Permeable porosities after seven days of exposure in deionized water and sulfuric acid.

\subsection{Corrosion-Layer Depth}

276 Addition of heavy metals in AACs resulted in a decrease of the corrosion-layer depth as shown in Figure

277 6. $\mathrm{Cu}$ and $\mathrm{Cu} / \mathrm{Co}$, respectively, decreased the corrosion-layer depth by $8 \%$ and $17 \%$. More specifically,

278 results demonstrate that addition of $\mathrm{Cu} / \mathrm{Co}$ reduced the average depth of the weak corrosion layer by

279 approximately $26 \%$ compared to the Control samples without heavy metal addition. 


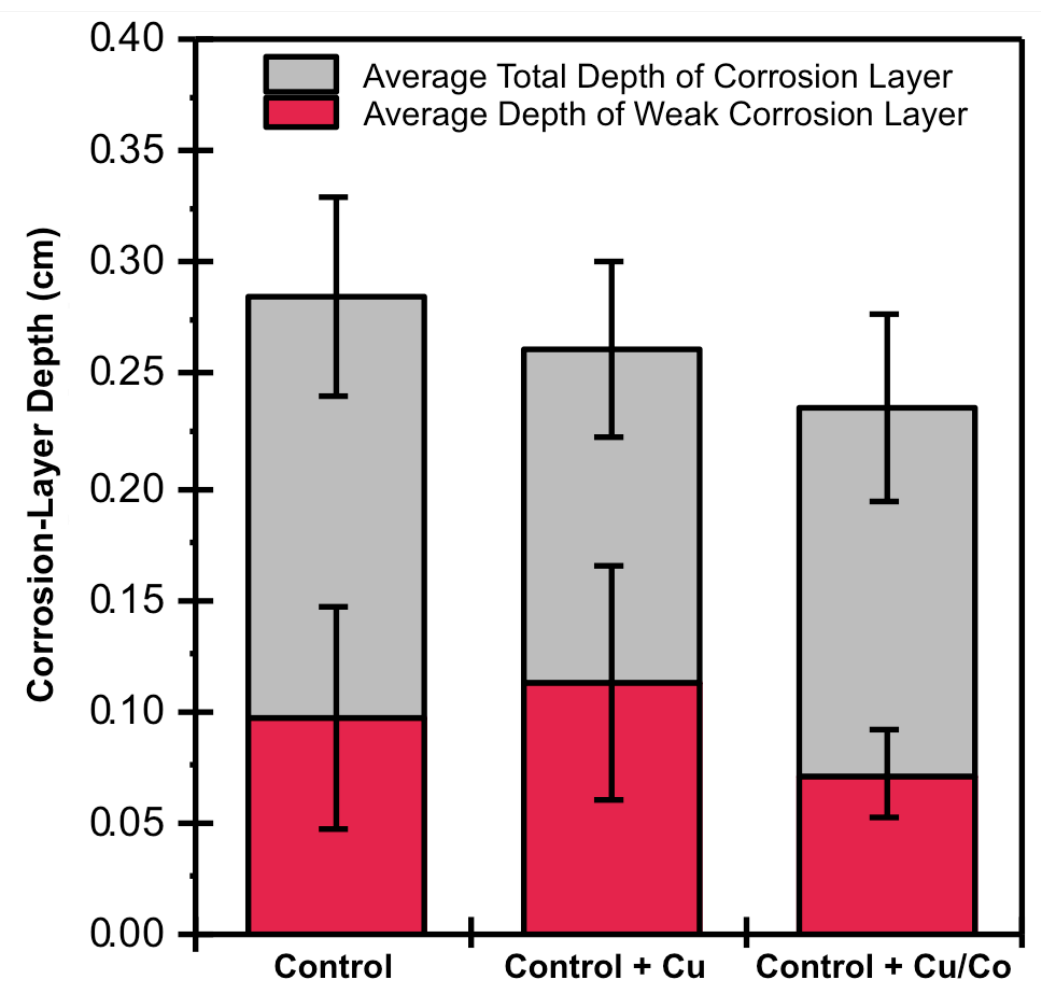

Figure 6. Corrosion-layer depth of all samples, including the thickness of weak corrosion layer, after seven days of exposure in sulfuric acid $(n=3)$.

\subsection{Elemental maps of AACs exposed to acid}

Elemental compositions of the AAC samples before and after seven days of sulfuric acid exposure are shown in Figure 7. As shown in Figure 7a, all samples have an initially homogeneous distribution of elements within the AAC microstructure before acid exposure.

After acid exposure, some similarities remain between samples (Figure 7b). Overlap between $\mathrm{Ca}, \mathrm{Fe}$, and $\mathrm{Mg}$ net intensity counts, for example, indicate the presence of unreacted mineral phases found in the BOF-slag precursor (see Figure 7a). Net elemental intensity counts between the different samples indicate different solid phases that form in response to acid exposure (Figure 7b). For example, after acid exposure, overlap between the net intensities of both $\mathrm{Ca}$ and sulfur (S) maps indicate precipitation of gypsum within cracks and pores of the AAC samples, corroborating evidence from the XRD patterns. In addition, the visually observable corrosion layer is depicted in each sample by the decalcification present in the Ca maps (Figure 7b).

Despite these similarities, many notable differences between formulations are evident after acid exposure. For instance, while acid exposure induces transience of Si and $\mathrm{Al}$ in all samples, the extent of their mobility and ultimate fate differ among samples. Si-rich bands developed with more distinct 
298 uniformity in samples containing $\mathrm{Cu}$ and $\mathrm{Co}$ (Figure 7b). Si in the Control sample is observed to form a

299 heterogeneous distribution of Si-rich areas. Dealumination (ejection of Al from the AAC binder) was

300 observed in all samples; however, as judged by elemental mapping, dealumination decreased in

301 formulations containing $\mathrm{Cu}$ and $\mathrm{Co}$. After acid exposure, cation mobility occurred past the border of what

302 macroscopically corresponded to the corrosion layer (Figure 7b). While Na was observed to leach out of

303 all AAC formulations, Na redistributed past the visually observable corrosion layer in the Control and

304 Control $+\mathrm{Cu}$ samples, while formulations containing both $\mathrm{Cu}$ and $\mathrm{Co}$ exhibited the highest $\mathrm{Na}$ leaching.

305 All samples demonstrated cationic dissolution and subsequent mobility of $\mathrm{Mg}$. Control and Control $+\mathrm{Cu}$

306 samples presented diffuse Mg-containing bands at the visually observable corrosion front, while samples

307 containing both $\mathrm{Cu}$ and $\mathrm{Co}$ exhibited homogeneous mobility of $\mathrm{Mg}$ past the visually observable corrosion

308 layer. Similar to the behavior of $\mathrm{Mg}$ in Control samples, Fe forms a diffuse band at the visually

309 observable corrosion front, yet in samples containing both $\mathrm{Cu}$ and $\mathrm{Co}$, Fe concentrated a double-layered

310 band at the same location. Inclusion of both $\mathrm{Cu}$ and $\mathrm{Co}$ resulted in their mobilization and formation of a

311 band at the visually observable corrosion front (Figure $7 \mathbf{b}$ ). $\mathrm{Cu}$, when included in any formulation,

312 created a $\mathrm{Cu}$-rich band, while $\mathrm{Co}$ accumulated as a band in the same position albeit by lesser net intensity

313 counts compared to $\mathrm{Cu}$. 


\section{Control}

(a)
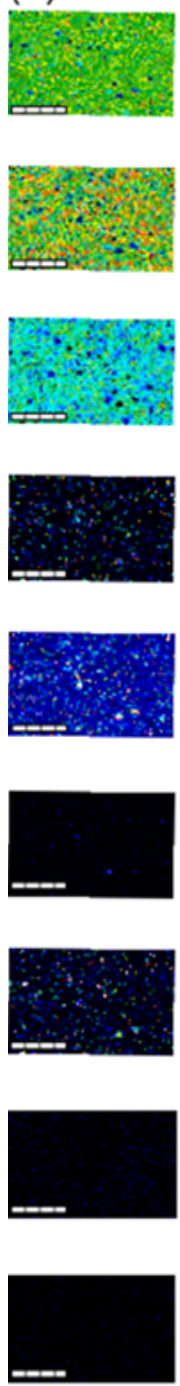

Control + Cu

(a)

(b)
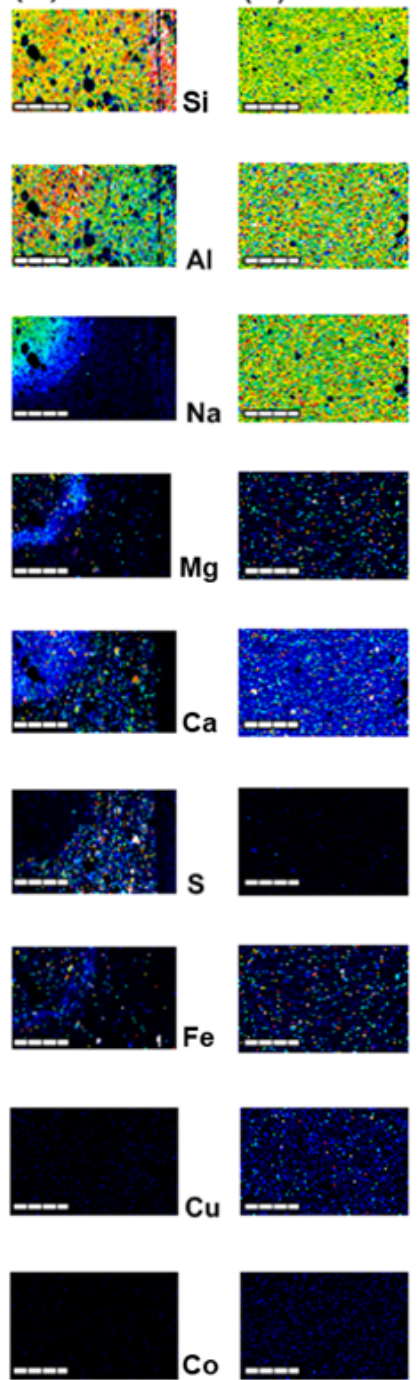

(b)
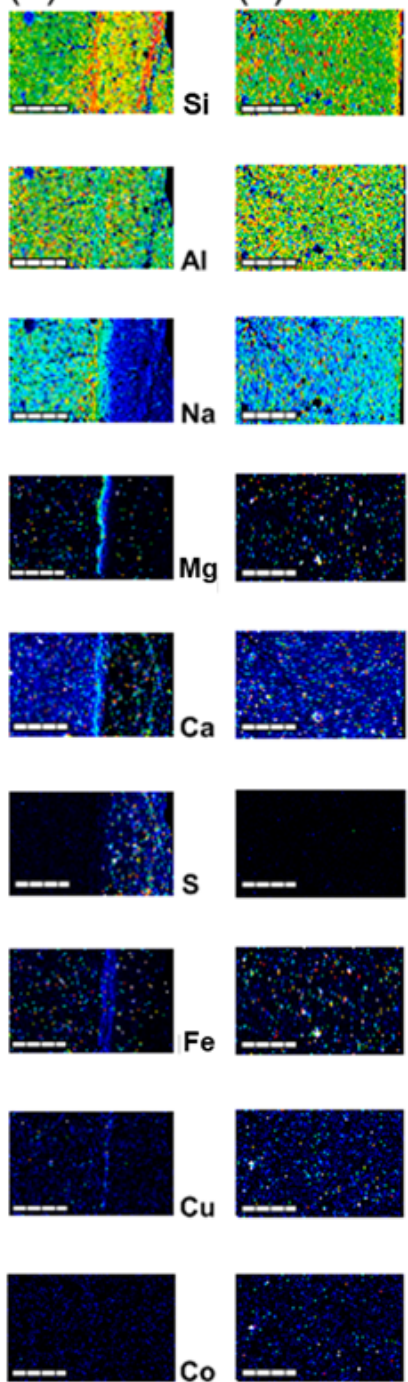

(a)
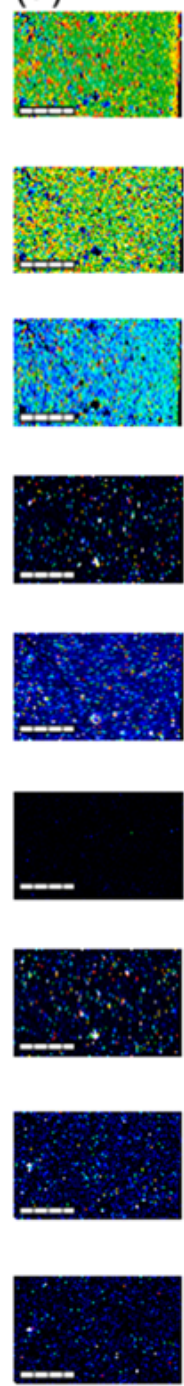

Control $+\mathrm{Cu} / \mathrm{Co}$

(b)
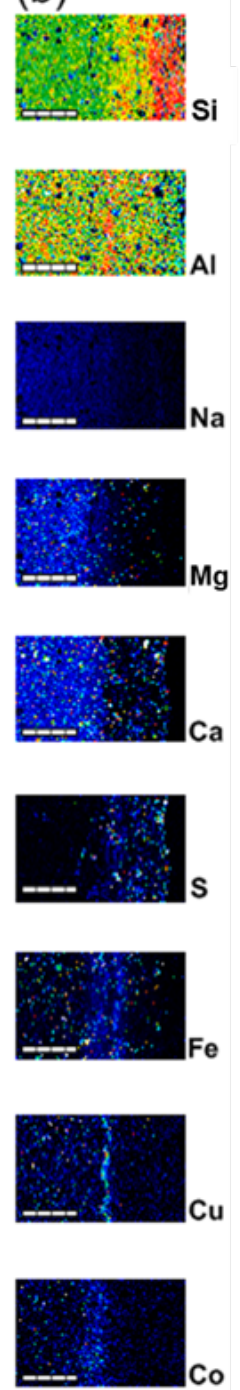

314 Figure 7. Elemental mapping of Control, Control $+\mathrm{Cu}$, Control $+\mathrm{Cu} / \mathrm{Co}$ samples when (a) unexposed to

315 acid and (b) after seven days of sulfuric acid exposure. Acid intrusion direction is from right to left. Scale

$316 \mathrm{bar}=1 \mathrm{~mm}$. Net-count color intensity scales are provided in the Supplementary Information.

317 4. Discussion

\section{$318 \quad 4.1$ Heavy metals modify AAC microstructure and properties}

319 Results from the desorption potential experiment indicate that a maximum of $98 \%$ of any heavy metal

320 element (i.e., $\mathrm{Cu}, \mathrm{Co}$ ) was liberated by the $\mathrm{Control}+\mathrm{Cu}$ and $\mathrm{Control}+\mathrm{Cu} / \mathrm{Co}$ formulations after exposure

321 to 6 eq of acid (Figure 2). In comparison, semi-dynamic leaching revealed lower leaching of both $\mathrm{Cu}$ and

322 Co (Figure 1). The difference in leaching behavior might indicate a complex behavior of heavy metals

323 exposed to acidic conditions, which may relate to heavy metals compensating charges within the

324 aluminosilicate framework. Similar heavy metal charge-compensation has been observed in [32] and [33] 
for multivalent heavy metals with +2 and +3 charges.

326 Heavy-metal modifications resulted in distinctive changes to material properties. All AAC samples 327 analyzed herein are composed of both C-S-H (Figure 3 and Figure 4) and N-A-S-H binders. This 328 observation has been similarly observed in studies of blended systems [34] and, in this study, it is due to 329 presence of belite (Supplementary Information) in the slag precursor and of reactive Si and Al in the 330 metakaolin precursor (Table 1). The inclusion of $\mathrm{Cu}$ and Co increased elemental leaching of both $\mathrm{Si}$ and $331 \mathrm{Na}$ in deionized water (Figure 1) as compared to the Control sample. Leaching of Si and $\mathrm{Na}$ ions in 332 AACs may be explained by a shift in equilibrium due to chemical reactions of free silicate monomers, 333 dimers, trimers, and alkali metals (i.e., $\mathrm{Na}$ ), as explained by [22]. Leaching of $\mathrm{Na}$ from the AAC 334 microstructure allows for the breakdown and mobility of unreacted Si monomers and oligomers. As a 335 result, higher leaching of $\mathrm{Si}$ and $\mathrm{Na}$ indicate that $\mathrm{Control}+\mathrm{Cu}$ and $\mathrm{Control}+\mathrm{Cu} / \mathrm{Co}$ samples may have 336 higher unreacted Si content. This finding is consistent with (1) prevailing theory that suggests that heavy337 metal cations (i.e., $\mathrm{Cu}, \mathrm{Co}$ ) aid in stabilization of negatively charged $\mathrm{Al}$ anions in the binder's Si-O-Al-O 338 chain, enhancing mobility of other cations (i.e., Na) [32], and (2) studies on NaSi gels with low $\mathrm{Si}$ 339 contents (low $\mathrm{SiO}_{2} / \mathrm{Na}_{2} \mathrm{O}$ molar ratios) that revealed higher $\mathrm{Si}$ leaching when exposed to deionized water

340 [35]. Finally, the addition of heavy metals reduces dealumination of AACs as evidenced by the 341 decreasing shifts in distributions of aluminum atoms (Figure 8) and decreased changes to the bulk Si:Al

342 ratios (Table 5) before and after acid exposure. Reductions in dealumination improves resistance to 343 changes in porosity due to sulfuric acid and deionized water exposure (Figure 5), retards gypsum 344 formation (Figure 3 and Figure 4), and reduces the observable corrosion depth when exposed to acid 345 (Figure 6). 

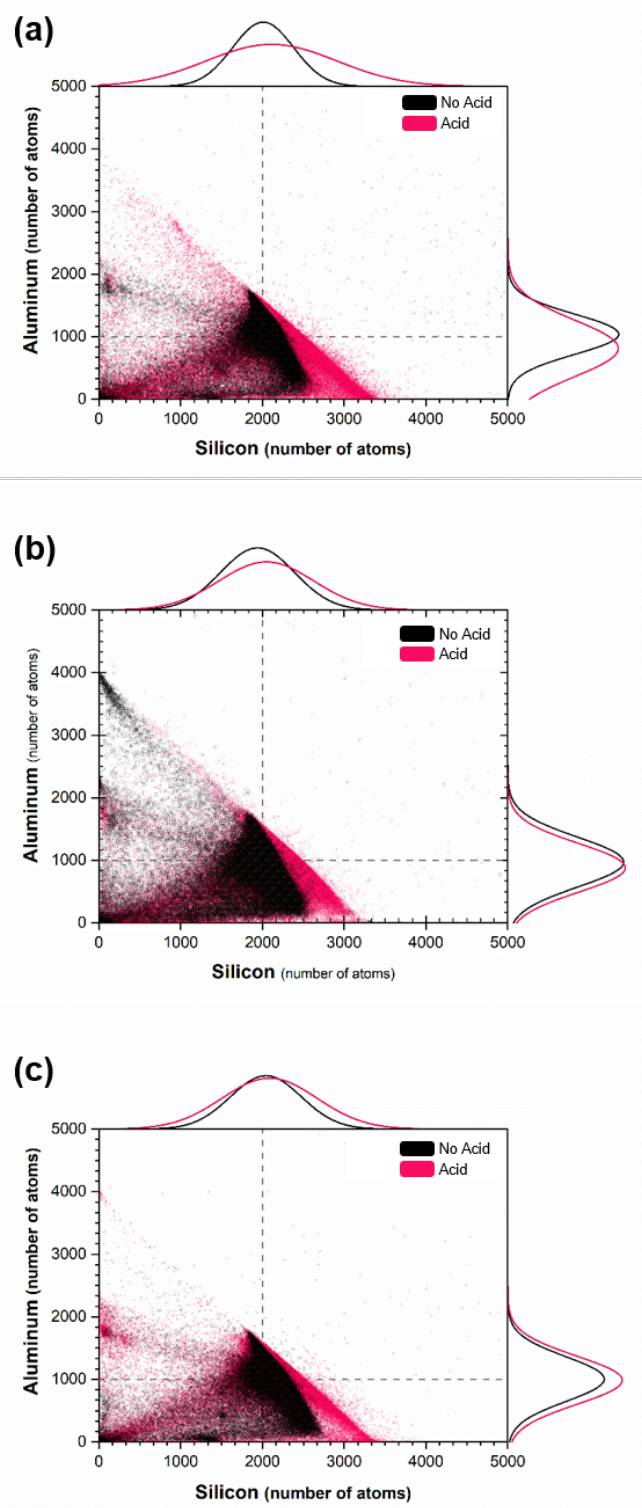

347 Figure 8. Number of silicon and aluminum atoms at each EMPA data point for (a) Control, (b) Control + $348 \mathrm{Cu}$, (c) Control $+\mathrm{Cu} / \mathrm{Co}$ samples before and after acid exposure. Cross section of lines within each plot 349 indicate a $\mathrm{Si}: \mathrm{Al}$ ratio of 2.0.

351 Table 5. Bulk Si:Al ratio means and medians derived from EMPA data.

\begin{tabular}{|lccc|lccc|}
\hline \multicolumn{3}{c}{ Unexposed } & & \multicolumn{4}{c|}{ Acid Exposed } \\
\hline \multicolumn{1}{|c}{ Sample } & Median & Mean & S.D. & \multicolumn{1}{c|}{ Sample } & Median & Mean & S.D. \\
\hline Control & 1.86 & 1.9 & 0.42 & Control & 2.43 & 2.57 & 1.01 \\
Control $+\mathrm{Cu}$ & 1.97 & 2.02 & 0.51 & Control $+\mathrm{Cu}$ & 2.29 & 2.42 & 0.84 \\
Control $+\mathrm{Cu} / \mathrm{Co}$ & 1.92 & 1.98 & 0.52 & Control $+\mathrm{Cu} / \mathrm{Co}$ & 1.96 & 2.08 & 0.79 \\
\hline
\end{tabular}


Manuscript submitted to:

Cement and Concrete Research

\subsection{Dissolution and precipitation reactions due to loss of pore structure}

Pore structure - and the preservation of the pore solution - is hypothesized to play an important role in the dissolution and precipitation reactions occurring during exposure to aggressive solutions. In this study, leaching of soluble phases or inducing mobility of ions in the AAC matrix enabled different mineral precipitation in acid. For example, ion dissolution yielded precipitation of gypsum when powdered samples were exposed to sulfuric acid (Figure 4). Contrastingly, cast samples with heavy metals resulted in retarded gypsum precipitation when exposed to acid (Figure 3). The different behavior of cast samples could be explained by the retention of the pore structure and preservation of the pore solution, which may reduce the initial dissolution and subsequent precipitation reactions. Similar observations have been reported in [36], where fly ash-based AAC samples retaining their pore structure during deionized water exposure exhibited lack of mineral formation.

\subsection{Acid degradation mechanisms}

While evidence consistent with prevailing acid degradation theory [13], [22] was observed heredealumination and decalcification - elemental mapping analysis of acid-stressed AACs containing $\mathrm{Cu}$ and Co indicate that other acid degradation mechanisms are possible in these materials. Differences in dealumination and decalcification were observed in the presence and absence of $\mathrm{Cu}$ and $\mathrm{Co}$ (Figure 7). For example, dealumination progressed in Control samples with the concomitant loss of Al from the microstructure, while decalcification was observed in all samples. These results suggest that the presence of heavy metals, such as $\mathrm{Co}$ and/or $\mathrm{Cu}$, can influence the extent and pathways of acid degradation in the following specific terms: (a) extent of $\mathrm{H}_{3} \mathrm{O}^{+}$penetration, (b) cationic mobility, fate, and stabilization of the AAC microstructure, and (c) formation of an acid passivation barrier.

\subsection{1 $\mathrm{H}_{3} \mathrm{O}^{+}$penetration into the AAC framework}

Experimental evidence confirms $\mathrm{H}_{3} \mathrm{O}^{+}$penetration past the visually observable corrosion layer, which may be responsible for inducing cationic mobility via mineral dissolution. For example, elemental mapping of $\mathrm{Mg}$ and Fe reveal mineral dissolution and subsequent cation mobility upon acid exposure past the visually observable corrosion layer in any sample, as defined by the decalcification fronts observable in the $\mathrm{Ca}$ elemental maps (Figure 7). In general, acid-induced mineral dissolution is caused by the presence of $\mathrm{H}_{3} \mathrm{O}^{+}$ions and their adsorption onto solid surfaces. The $\mathrm{H}_{3} \mathrm{O}^{+}$-induced dissolution of $\mathrm{Mg}$ - and $\mathrm{Fe}-$ containing minerals observed herein (Figure 3) is likely similar to the dissolution of forsterite, a magnesium silicate mineral. In acid-induced forsterite dissolution, three hydrogen atoms of an hydronium ion dissolve the mineral by associating with two bridging oxygen atoms and liberating the $\mathrm{Mg}$ cation [37]. Furthermore, other studies have validated the role of $\mathrm{H}_{3} \mathrm{O}^{+}$ions on the dissolution of Fe-containing mineral phases [38]. Therefore, given that $\mathrm{H}_{3} \mathrm{O}^{+}$ions play an important role in the occurrence and rate of both Mg- and Fe-containing mineral dissolution [39], its deeper presence within the aluminosilicate 
framework indeed would induce both mineral dissolution and cationic mobility.

\subsubsection{Cationic mobility, fate, and stabilization of AAC microstructure}

Results indicate that the mobility of cations (e.g., $\mathrm{Mg}, \mathrm{Fe}$ ) within the microstructure may influence the leaching of other cations (e.g., $\mathrm{Na}$ ). When exposed to sulfuric acid, $\mathrm{Cu} / \mathrm{Co}$-containing samples leached the most $\mathrm{Na}$ of all AACs (Figure 1). Complementary to these results, Figure 7b indicates the absence of $\mathrm{Na}$ in corroded regions. Absence of Na charge-balancing cations may be exacerbated by the mobility of other cations within the microstructure, such as $\mathrm{Mg}$ from merwinite minerals (Figure 3), and potential binder charge-compensation by $\mathrm{Cu}$ and $\mathrm{Co}$, as explained previously. For example, the quantity of free $\mathrm{Mg}$ cations can be observed to increase in areas of high Na leaching (Figure 7b). Furthermore, in samples incorporating $\mathrm{Cu}$ and $\mathrm{Co}$, the release of $\mathrm{Na}$ atoms may be preferential in these samples and, also, may not compromise acid resistance due to extensive cationic mobility of $\mathrm{Mg}$, as further discussed in the following paragraph. These observations not only further provide evidence of cationic mobility past the visually observable corrosion layer, but also help explain the findings reported in [39], which show that high alkali contents improve the acid resistance of AACs.

Cationic dissolution from minerals (Figure 3) and subsequent retention of cations within the AAC framework stabilizes the binder and prevents further deterioration in acid. As previously discussed, $\mathrm{Mg}$ elemental maps (Figure 7) show the dissolution of $\mathrm{Mg}$ mineral phases (merwinite) past the visually observable corrosion depth (decalcified front).At these same depths, cation mobility is also observed in samples incorporating $\mathrm{Cu}$ and $\mathrm{Co}$. These heavy metal-containing samples exhibit lower porosity changes after acid challenges and yield lower amounts of corrosion product as judged by caliper measurements (see Figure 5 and Figure 6). Based on these results, it is hypothesized that the released cations may act as replacements for the initial charge-balancing cations (primarily $\mathrm{Ca}$ and $\mathrm{Na}$ ), whose weak bonds with $\mathrm{Al}$ in the binder can be replaced by hydronium ions penetrating the AAC matrix [40]. In this context, the inclusion of diffusible $\mathrm{Cu}$ and $\mathrm{Co}$ as supplementary cations appear to play an important role in inhibiting electrophilic attack of AAC binders by $\mathrm{H}_{3} \mathrm{O}^{+}$ions [17].

\subsubsection{Passivation barrier formation}

$\mathrm{Fe}, \mathrm{Cu}$, and $\mathrm{Co}$ cations appear to form a passivation barrier, which may help reduce the extent of dealumination and improve the acid resistance of AACs. After seven days of acid exposure, AAC samples with heavy metals concentrated in bands with other cations at the degradation front (see Figure 7). Complementary to these results, these samples exhibited the lowest porosity changes and smallest corrosion depth compared to the otherwise identical Control samples (Figure 5, Figure 6). These observations are novel, as the role of Fe in AACs, and, especially, their role in acid degradation, has not been fully explored, with only limited studies demonstrating reductions in the local Fe coordination after alkali activation [41]-[43]. 
The proposed mechanism of acid degradation is illustrated in Figure 9. Complementary to existing 422 acid degradation theory, the presence of a passivation barrier is hypothesized to create different $\mathrm{pH}$ and 423 silica concentration conditions within the AAC microstructure, which affect the stability of silica gels in 424 acidic conditions. During acid challenges, electrophilic attack of $\mathrm{Si}-\mathrm{O}-\mathrm{Al}$ bonds by $\mathrm{H}_{3} \mathrm{O}^{+}$ions (reaction 1) 425 [13], and subsequent decalcification results in dealumination (reaction 2a). Given the data presented in 426 this study, it is evidenced that dealumination competes with a process of cation stabilization $\left(\mathrm{Mg}^{+2}, \mathrm{Fe}^{+3}\right.$, $427 \mathrm{Ca}^{+2}$ ), as presented in reaction $\mathbf{2 b}$ and demonstrated by Figure 7. After dealumination, formation of a 428 protective layer of polymerized silica has been observed (reaction 3a) [44]; this gel is believed to be less 429 porous and aids in the retention of cations, promoting acid resistance. Previously, a set of balanced 430 equilibrium reactions was proposed to describe the polymerization of silica species and subsequent 431 formation of silica gels at low $\mathrm{pH}$ values [22]. However, the polymerization and, later, gelation of silica 432 species is a $\mathrm{pH}$ - and concentration-dependent process based on chemical equilibrium, which has not been 433 previously considered in [22]. The fundamental chemistry of silica has previously been explained in detail 434 [45], where polymerization of silica at $\mathrm{pH}$ 2-7 is described in the following steps: (1) polymerization of 435 silica monomers (orthosilicic acid) to dimers, trimers, cyclic oligomers, and particles, (2) slow particle 436 growth reaching a diameter of 2-3 nm, and (3) collision or aggregation of silica particles into chains and 437 then gel networks. The aforementioned steps are limited by the concentration of orthosilicic acid 438 monomers in solution, which, if maintained above its solubility concentration limit, permits silica 439 polymerization and particle growth, as described by nucleation theory [46] (reaction 3b). 
(1)<smiles>CCO[Si](O)(O)O[N+](O)([18OH])O[Si](O)(O)OCC</smiles>

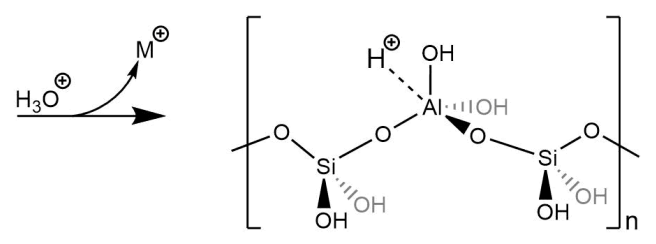

(2a)

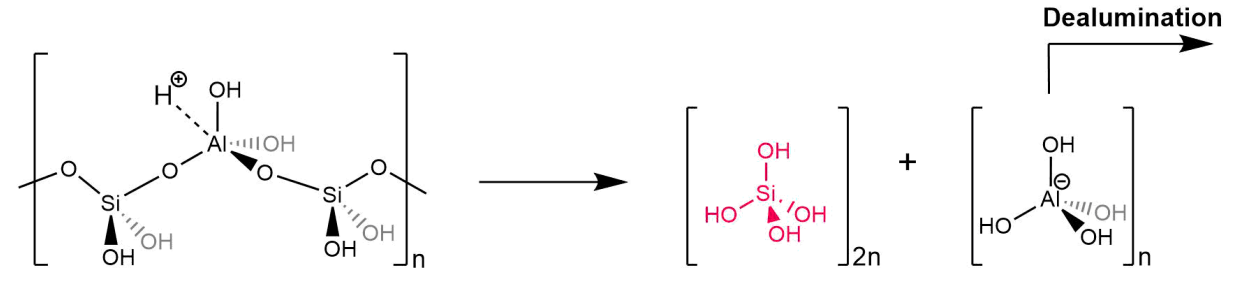

(2b)

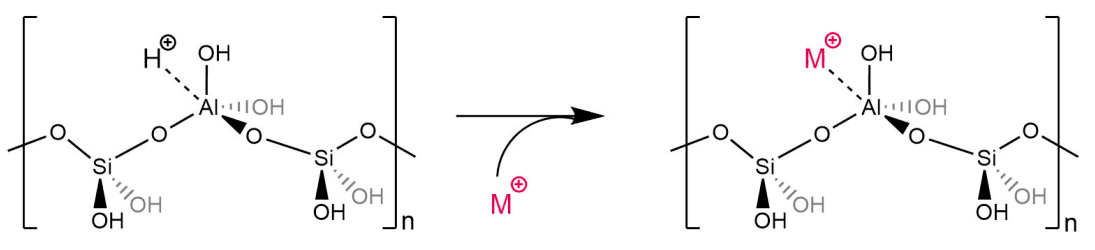

(3a)

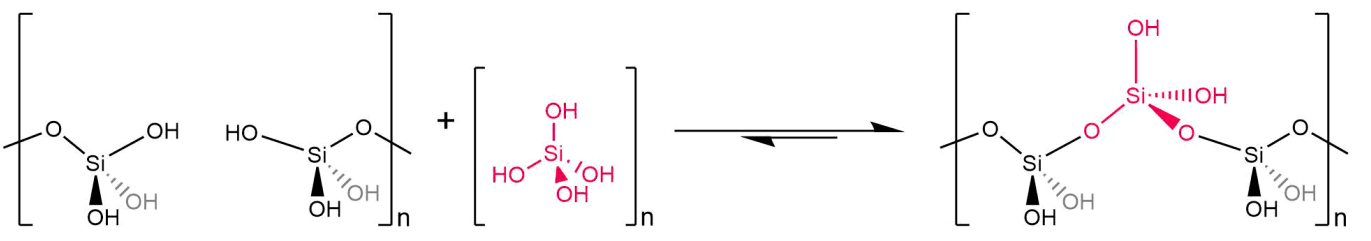

(3b)

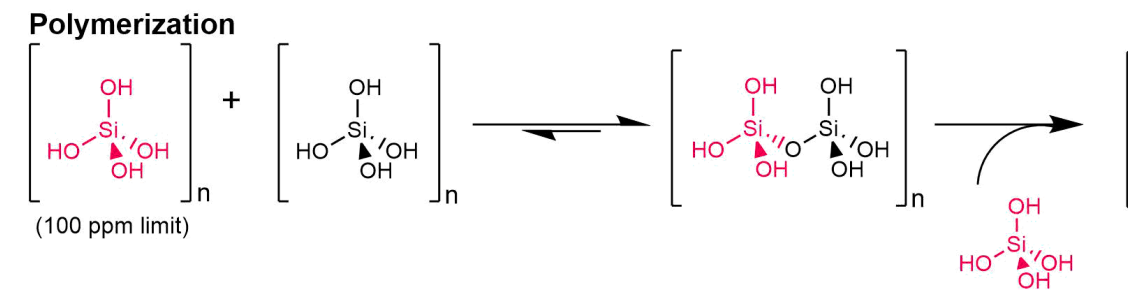

(4)
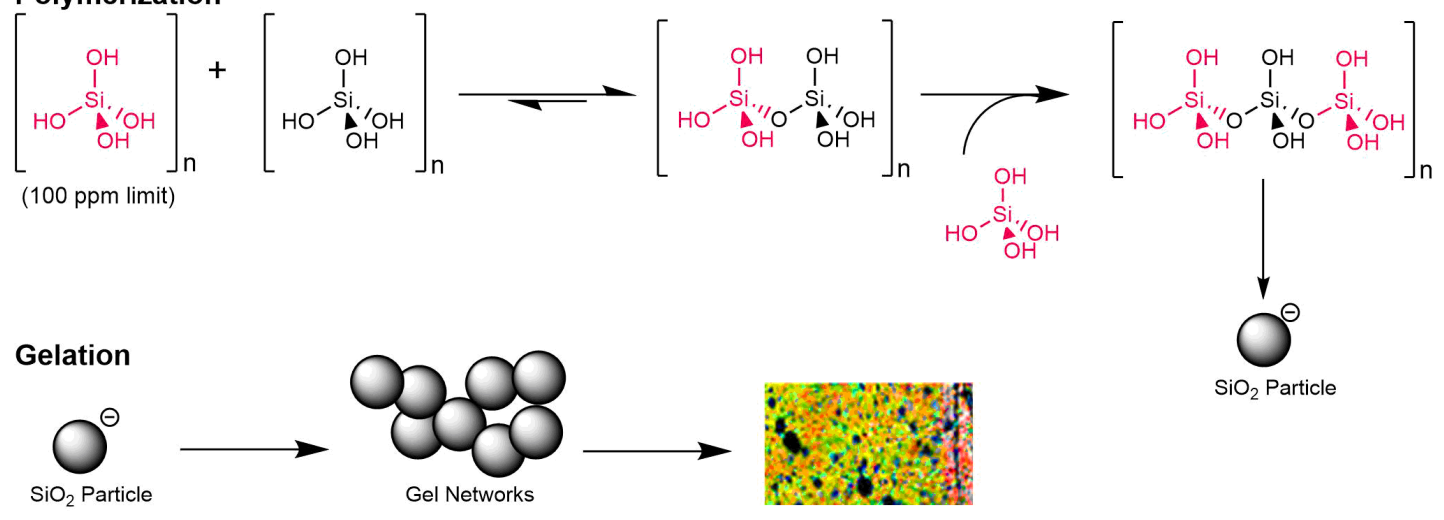

Figure 9. Proposed mechanism of acid degradation.

The presence of multivalent cations $\left(\mathrm{Mg}^{+2}, \mathrm{Fe}^{+3}, \mathrm{Ca}^{+2}, \mathrm{Co}^{+2}, \mathrm{Cu}^{+2}\right)$ within the AAC microstructure affects both (1) the stability of silica species and (2) $\mathrm{pH}$ conditions, which may be further promoted via creation of the passivation barrier. As a result, these two concurrent conditions may permit the formation of stratified silica gels. Evidence, presented in [44], demonstrates the ability of heavy metals in solution to

448 favor the stability of polymeric silica species and retard depolymerization into orthosilicic monomers. The 
higher stability of polymeric silica species may enhance silica mobility to the periphery of AAC samples as facilitated by diffusion (Figure 7). Subsequently, depending on the concentration, the presence of multivalent cations $\left(\mathrm{Mg}^{+2}, \mathrm{Fe}^{+3}, \mathrm{Ca}^{+2}, \mathrm{Co}^{+2}, \mathrm{Cu}^{+2}\right)$ decreases the rate and size of silica particle aggregation due to silica particle stabilization, as described in [45]-[47]. The semi-dynamic leaching data, presented in Figure 1, demonstrates lower leaching of multivalent cations. These results suggest that particle aggregation size and rate is decreased, which may further enhance the mobility of smaller silica particle aggregates to the periphery of the material. As silica species mobilize to the periphery, if the $\mathrm{pH}$ within the AAC microstructure is lower, then polymerization of silica monomers (reaction $3 \mathbf{b}$ ) and gelation of silica particles (reaction 4) is expected to increase, as described in [48], [49]. Additionally, the former two conditions (silica stability and $\mathrm{pH}$ ) may be further maintained by the formation of the passivation barrier, thus, aiding the stratified formation of silica gels at the periphery (Figure 7). Benefiting the acid resistance of AACs, the formation of silica gels may serve as an adequate protective, non-porous, and impermeable layer [50]. Inversely, in AAC samples without heavy metals, previously mentioned $\mathrm{pH}$ or silica conditions may not be present due to the lower content of multivalent cations and absence of a passivation barrier. Instead, sporadic and randomized gelation may be preferred throughout the AAC microstructure (Figure 7). In summary, the experimental evidence presented here suggests an alternate pathway for the formation of a stratified silica-rich gel in the presence of heavy metals during acid degradation- one that depends on the presence of multivalent cations, $\mathrm{pH}$ conditions, and silica speciation.

\section{Conclusion}

The aim of this study was to investigate the effect of heavy metals, namely copper $(\mathrm{Cu})$ and cobalt $(\mathrm{Co})$, on the acid resistance of AACs. In this study, adsorption of $\mathrm{Cu}$ and $\mathrm{Co}$ onto a basic oxygen furnace slag (BOF-S) precursor improved the acid resistance of binary metakaolin and BOF-S-based AACs.

This study resulted in the following significant findings:

1. AACs micro-doped with $\mathrm{Cu}$ and $\mathrm{Co}$ inhibited the rate of calcium sulfate mineral formation, resulting in lower permeable porosities and smaller corrosion depths;

2. Hydronium ions were evident within the AAC framework and extended beyond the visually observable corrosion front;

3. Hydronium ion penetration was associated with increased cation mobility; mobile cations aided in the stabilization of cementitious binders;

4. $\mathrm{Fe}, \mathrm{Cu}$, and $\mathrm{Co}$ ions formed passivation barriers at the acid degradation front, suggesting they play a critical role in reducing the extent of dealumination and improving the acid resistance of AACs; 
5. A stratified silica-rich gel was observed in AACs containing $\mathrm{Cu}$ and $\mathrm{Co}$; the formation of this gel is likely dependent on the presence of multivalent cations, $\mathrm{pH}$ conditions, and silica speciation.

Together, these data provide new experimental evidence of a more complex AAC acid degradation mechanism than previously observed.

\section{Acknowledgments}

This research was made possible by the Department of Civil, Environmental, and Architectural Engineering, the College of Engineering and Applied Sciences, and the Sustainable Infrastructure Materials Laboratory (SIMLab) at the University of Colorado Boulder. This work was supported by the National Science Foundation grants CBET-1604457 and EAR-1427626. Dr. Kate Campbell and Mr. Tyler Kane of the United States Geological Survey (USGS) are gratefully acknowledged for their insights and assistance with XRD. Dr. Julien Allaz in the Department of Geological Sciences at the University of Colorado Boulder is also gratefully acknowledged for his assistance with EMPA. This work represents the views of the authors and not necessarily those of the sponsors.

\section{References}

[1] B. Huber, H. Hilbig, J. E. Drewes, and E. Muller, "Evaluation of concrete corrosion after shortand long-term exposure to chemically and microbially generated sulfuric acid," Cem. Concr. Res., vol. 94, pp. 36-48, 2017.

[2] U.S. Environmental Protection Agency (EPA), “Clean Watersheds Needs Survey - Report to Congress," 2008.

[3] American Society of Civil Engineers (ASCE) Foundation, "2017 Wastewater Infrastructure Report Card," 2017.

[4] C. Grengg, F. Mittermayr, A. Baldermann, M. E. Bottcher, A. Leis, G. Koreimann, and M. Dietzel, "Bacteriogenically Induced Sulfuric Acid Attack on Concrete in an Austrian Sewer System," in XIII Conference on Durability of Building Materials and Components, 2017, pp. 897903.

[5] C. D. Parker, "Mechanics of Corrosion of Concrete Sewers by Hydrogen Sulfide," Sewage Ind. Waste., vol. 23, no. 12, pp. 1477-1485, 1951.

[6] A. L. Ling, C. E. Robertson, J. K. Harris, D. N. Frank, C. V. Kotter, M. J. Stevens, N. R. Pace, and M. T. Hernandez, "High-resolution microbial community succession of microbially induced concrete corrosion in working sanitary manholes," PLoS One, vol. 10, no. 3, pp. 1-12, 2015.

[7] J. Vollertsen, A. H. Nielsen, H. S. Jensen, T. Wium-Andersen, and T. Hvitved-Jacobsen, "Corrosion of concrete sewers-The kinetics of hydrogen sulfide oxidation," Sci. Total Environ., vol. 394, no. 1, pp. 162-170, 2008.

[8] R. Sterling, J. Simicevic, E. Allouche, W. Condit, and L. Wang, "State of Technology for 
Rehabilitation of Wastewater Collection Systems," 2010.

[9] E. Hewayde, M. L. Nehdi, E. Allouche, and G. Nakhla, "Using concrete admixtures for sulphuric acid resistance," Proc. Inst. Civ. Eng. - Constr. Mater., vol. 160, no. 1, pp. 25-35, 2007.

[10] W. De Muynck, N. De Belie, and W. Verstraete, "Effectiveness of admixtures, surface treatments and antimicrobial compounds against biogenic sulfuric acid corrosion of concrete," Cem. Concr. Compos., vol. 31, no. 3, pp. 163-170, 2009.

[11] B. Hashemi, T. Iseley, and J. Raulston, "Water Pipeline Renewal Evaluation Using AWWA Class IV CIPP, Pipe Bursting, and Open-Cut,” in ICPTT 2011 ASCE, 2011, pp. 1257-1266.

[12] C. Shi, A. F. Jiménez, and A. Palomo, "New cements for the 21 st century: The pursuit of an alternative to Portland cement," Cem. Concr. Res., vol. 41, no. 7, pp. 750-763, 2011.

[13] A. Allahverdi and F. Škvára, "Sulfuric acid attack on hardened paste of geopolymer cements-Part 1. Mechanism of corrosion at relatively high concentrations," Ceram. - Silikaty, vol. 49, no. 4, p. $225,2005$.

[14] A. Allahverdi and F. Škvára, "Sulfuric acid attack on hardened paste of geopolymer cements Part

2. Corrosion mechanism at mild and relatively low concentrations," Ceram. - Silikaty, vol. 50, no. 1, pp. 1-4, 2006.

[15] A. Allahverdi and F. Škvára, "Nitric acid attack on hardened paste of geopolymeric cements. Part 2,” Ceram. - Silikaty, vol. 45, no. 4, pp. 143-149, 2001.

[16] A. Allahverdi and F. Škvára, "Nitric acid attack on hardened paste of geopolymeric cements. Part 1.," Ceram. - Silikaty, vol. 45, no. 4, pp. 143-149, 2001.

[17] A. Allahverdi and F. Škvára, “Acid Corrosion of Geopolymeric Cements," in Seventh CANMET/ACI International Conference on fly ash, silica fume, and natural pozzolans in concrete, 2001, vol. 2, pp. 561-579.

[18] S. A. Bernal, E. D. Rodríguez, R. Mejía, R. Mejía De Gutiérrez, and J. L. Provis, "Performance of alkali-activated slag mortars exposed to acids Performance of alkali-activated slag mortars exposed to acids," J. Sustain. Cem. Mater., vol. 1, no. 3, 2012.

[19] T. Bakharev, J. G. Sanjayan, and Y. B. Cheng, "Resistance of alkali-activated slag concrete to acid attack," Cem. Concr. Res., vol. 33, no. 10, pp. 1607-1611, 2003.

[20] C. Shi and J. . A. Stegemann, "Acid corrosion resistance of different cementing materials," Cem. Concr. Res., vol. 30, no. 5, pp. 803-808, 2000.

[21] M. A. M. Ariffin, M. A. R. Bhutta, M. W. Hussin, M. M. Tahir, and N. Aziah, "Sulfuric acid resistance of blended ash geopolymer concrete," Constr. Build. Mater., vol. 43, pp. 80-86, 2013.

[22] T. Bakharev, "Resistance of geopolymer materials to acid attack," Cem. Concr. Res., vol. 35, no. 4, pp. 658-670, 2005. 
[23] R. Sathia, K. Ganesh Babu, and M. Santhanam, "Durability Study of Low Calcium Fly Ash Geopolymer Concrete," in The 3rd ACF International Conference- $A C F / V C A, 2008$, pp. 11531159.

[24] F. Pacheco-Torgal, Z. Abdollahnejad, a. F. Camões, M. Jamshidi, and Y. Ding, "Durability of alkali-activated binders: A clear advantage over Portland cement or an unproven issue?," Constr. Build. Mater., vol. 30, pp. 400-405, 2012.

[25] A. Caicedo-Ramirez, A. L. Ling, and M. Hernandez, "Diffusion susceptibility demonstrates relative inhibition potential of sorbent-immobilized heavy metals against sulfur oxidizing acidophiles," J. Microbiol. Methods, vol. 131, pp. 42-44, 2016.

[26] R. F. Farrell, S. A. Matthes, and A. J. Mackie, "A simple, low-cost method for the dissolution of metal mineral samples in plastic pressure vessels," U.S. Bur. Mines Rep., no. BM-RI-8480, p. 19, 1980.

[27] M. Torres-Carrasco and F. Puertas, "Waste glass in the geopolymer preparation. Mechanical and microstructural characterisation," J. Clean. Prod., vol. 90, pp. 397-408, 2015.

[28] D. D. Eberl, "User Guide to RockJock- A program for determining quantitative mineralogy from X-ray diffraction Data," U.S. Geol. Surv. Open-File Rep., p. 47, 2003.

[29] M. Safiuddin and N. Hearn, "Comparison of ASTM saturation techniques for measuring the permeable porosity of concrete," Cem. Concr. Res., vol. 35, no. 5, pp. 1008-1013, 2005.

[30] J. J. Donovan and T. N. Tingle, "An improved mean atomic number background correction for quantitative microanalysis," Microsc. Microanal., vol. 2, no. 1, pp. 1-7, Feb. 1996.

[31] J. Goldstein, D. Newbury, D. Joy, C. Lyman, P. Echlin, E. Lifshin, L. Sawyer, and J. Michael, Scanning Electron Microscopy and X-Ray Microanalysis, 3rd ed., vol. 53, no. 9. Springer Science+Business Media, LLC, 2013.

[32] F. Škvára, L. Kopecky, V. Smilauer, and Z. Bittnar, "Material and structural characterization of alkali activated low-calcium brown coal fly ash," J. Hazard. Mater., vol. 168, pp. 711-720, 2009.

[33] N. Waijarean, K. J. D. Mackenzie, S. Asavapisit, R. Piyaphanuwat, and G. N. L. Jameson, "Synthesis and properties of geopolymers based on water treatment residue and their immobilization of some heavy metals," J. Mater. Sci., vol. 52, no. 12, pp. 7345-7359, 2017.

[34] J. L. Provis and J. S. J. van Deventer, "Alkali Activated Materials, State-of-the-Art Report, RILEM TC 224-AAM,” Springer US, 2014.

[35] D. Dimas, I. Giannopoulou, and D. Panias, "Polymerization in sodium silicate solutions: A fundamental process in geopolymerization technology," J. Mater. Sci., vol. 44, no. 14, pp. 3719 $3730,2009$.

[36] A. Fernandez-Jimenez, I. García-Lodeiro, and A. Palomo, "Durability of alkali-activated fly ash 
cementitious materials,” J. Mater. Sci., 2007.

[37] J. J. Rosso and D. J. Rimstidt, “A high resolution study of forsterite dissolution rates," Geochim. Cosmochim. Acta, vol. 64, no. 5, pp. 797-811, 2000.

[38] D. Baron and C. D. Palmer, "Solubility of KFe3 (CrO4)2(OH)6 at 4 to $35{ }^{\circ} \mathrm{C}$," Geochim. Cosmochim. Acta, vol. 60, no. 20, pp. 3815-3824, 1996.

[39] S. A. Carroll-Webb and J. V Walther, "A surface complex reaction model for the pH-dependence of corundum and kaolinite dissolution rates," Geochim. Cosmochim. Acta, vol. 52, pp. 2609-2623, 1988.

[40] F. Škvára, V. Šmilauer, P. Hlavácek, L. Kopecky, and Z. Cilová, “A Weak Alkali Bond in (N,K)A-S-H Gels: Evidence from Leaching and Modeling," Ceram. - Silikáty, vol. 56, no. 4, pp. 374$382,2012$.

[41] S. Noor, H. Guy, N. L. J. Joanne, and K. J. D. Mackenzie, "Synthesis and properties of inorganic polymers ( geopolymers ) derived from Bayer process residue ( red mud ) and bauxite,” J. Mater. Sci., vol. 50, no. 23, pp. 7713-7724, 2015.

[42] D. S. Perera, J. D. Cashion, M. G. Blackford, Z. Zhang, and E. R. Vance, "Fe speciation in geopolymers with Si/Al molar ratio of 2,” J. Eur. Ceram. Soc., vol. 27, no. 7, pp. 2697-2703, 2007.

[43] P. N. Lemougna, K. J. D. MacKenzie, G. N. L. Jameson, H. Rahier, and U. F. Chinje Melo, “The role of iron in the formation of inorganic polymers (geopolymers) from volcanic ash: A 57Fe Mossbauer spectroscopy study,” J. Mater. Sci., vol. 48, no. 15, pp. 5280-5286, 2013.

[44] M. Dietzel, "Dissolution of silicates and the stability of polysilicic acid," Geochim. Cosmochim. Acta, vol. 64, no. 19, pp. 3275-3281, 2000.

[45] R. K. Iler, Chemistry of Silica - Solubility, Polymerization, Colloid and Surface Properties and Biochemistry. Hoboken, NJ: John Wiley \& Sons, 1979.

[46] P. W. J. G. Wijnen, T. P. M. Beelen, and R. A. Van Santen, "Silica Gels from Aqueous Silicate Solutions," in The Colloid Chemistry of Silica, vol. 234, American Chemical Society, 1994, pp. $26-517$.

[47] F. Gaboriaud, D. Chaumont, A. Nonat, B. Hanquet, and A. Craeivich, "Study of the Influence of Alkaline Ions ( $\mathrm{Li}, \mathrm{Na}$ and $\mathrm{K}$ ) on the Structure of the Silicate Entities in Silico Alkaline Sol and on the Formation of the Silico-Calco-Alkaline Gel,” J. Sol-Gel Sci. Technol., vol. 13, no. 1-3, p. 353, 1998.

[48] J. Nordström, E. Nilsson, P. Jarvol, M. Nayeri, A. Palmqvist, J. Bergenholtz, and A. Matic, "Concentration- and $\mathrm{pH}-$ dependence of highly alkaline sodium silicate solutions," J. Colloid Interface Sci., vol. 356, no. 1, pp. 37-45, 2011. 
619 [49] C. O. Metin, L. W. Lake, C. R. Miranda, and Q. P. Nguyen, "Stability of aqueous silica nanoparticle dispersions," J. Nanoparticle Res., vol. 13, no. 2, pp. 839-850, 2011.

621 [50] M. M. Komljenovic, Z. Bascarevic, N. Marjanovic, and V. Nikolic, "Decalcification resistance of 622 alkali-activated slag," J. Hazard. Mater., vol. 234, pp. 112-121, 2012. 